improved our patient's morbid jealousy did not convince him, and indeed, he seems to believe that we actually missed an alcoholic in the process. The facts of the matter are these: the patient was not an alcoholic, although he did take alcohol at least once per week, and he would have been treated as such were such a condition present. The patient responded well to pimozide, at the dosage stated, and remained symptom-free for 5 months. At that time, he chose to discontinue his pimozide therapy, and the pathological jealousy re-emerged. Pimozide was once again used, with an excellent response again being noted. The patient had taken no alcohol for several months at that time, and there was no question of ethanol being involved in the syndrome. These details might serve to convince Dr Cohen of the efficacy of this preparation in the treatment of this syndrome.

Lamentably, alcoholism is all too frequently seen in our country, and had it been present in this situation, the problem would have been addressed. Dr Cohen is correct in assuming that drinking is discouraged among alcoholics on admission to our unit but this patient's symptoms could not be attributed to that cause, and he was not managed along the lines suggested, for this very reason.

Alberta Hospital Ponoka

Alan Byrne

Box 1000, Ponoka, Alberta

Canada TOC $2 \mathrm{HO}$

\section{Zinc taste test and postnatal depression}

SIR: Bryce-Smith \& Simpson (1984) have reported isolated patients with anorexia nervosa and "other depressive or neurotic states" being unable to taste a dilute zinc solution and responding to subsequent treatment with zinc sulphate, resulting in improved taste and mood. Additionally, there have been suggestions that postnatal depression may be linked to low levels of zinc caused by the demands of pregnancy, childbirth (with loss of placental zinc), and lactation, exacerbated by low dietary intake of zinc and by stress (Meadows et al, 1981; Ministry of Agriculture, Fisheries and Food, 1981; Cousins, 1986). Inability to taste a very dilute solution of zinc sulphate (the zinc taste test) has been proposed as a screening tool for identifying zinc deficiency.

We would like to report two investigations which question the association between postnatal depression and failure of the zinc taste test.

The first was in 12 patients being treated in a psychiatric unit for various forms of severe postnatal depression who were given the zinc taste test as described by Bryce-Smith \& Simpson at between 2 and
30 weeks after delivery $($ Mean $=11$ weeks). Seven reported no or a weak taste and five a positive or strong taste. According to Bryce-Smith \& Simpson's (1984) criteria, no taste or a weak aftertaste would indicate a poor zinc status. In practice, it is very difficult to differentiate between "an aftertaste with no taste immediately apparent" and a "definite taste which intensifies with time". Many of the mothers found it difficult to describe the taste sensation. Only one of the patients reporting a weak taste (different from water) said that she could not taste anything initially, and it is notable that only one patient showed a complete inability to taste.

The second investigation was a prospective population study starting in mid-pregnancy, and involved less severe forms of postnatal depression. Mothers returned a questionnaire, some weeks after delivery, containing the Irritability, Depression, Anxiety Scale (Snaith et al, 1978), the subscales of which were combined to give a total depression score. Seventy-six per cent of these were returned between 9 and 19 weeks postpartum.

Of all the patients, $20 \%$ scored over 16 on the depression scale and were judged to be showing signs of mild to moderate postnatal depression. Higher scores were equated with increased severity of depression, and $9 \%$ scored over 20 .

A total of 337 of these mothers had had the zinc taste test administered within 48 hours of delivery. The taste test was carried out as before, with the responses divided into 'tasters' and 'non-tasters'. Two hundred and ninety-seven patients who could taste the zinc solution returned depression scores with a mean of $11.33 \pm 6.7$, and 40 non-tasters returned a lower but not significantly different mean score of $10.75 \pm 5.6$.

We conclude, from unselected population data, that the zinc taste test is not useful as a predictive test for mothers suffering from post-natal depression. Zinc solutions are being marketed with claims of both diagnostic and therapeutic value. We feel that there is no evidence at present to support this practice in relation to postnatal depression.

Department of Child Health

P. M. MARKovits

University of Bristol, Bristol BS2 8BJ

Mother \& Baby Unit

A. W. SANKey

Barrow Hospital, Avon

D. K. JAMES

R. MCCABE

K. MAHOMED

J. GOLDING

University Department of Obstetrics \& Gynaecology

Bristol 


\section{Reforences}

Bryce-SMITh, D. \& Simpson, R. I. D. (1984) Anorexia, depression and zinc deficiency. Lancet, il, 1162.

Cousins, R. J. (1986) Zinc metabolism - co-ordinate regulation as related to cellular function. Proceedings of the XIII International Congress on Nutrition, pp. 500-504. London: John Libbey.

MEAdOWS, N. J., Ruse, W., SMath, M. F., et al (1981) Zinc and small babies. Lancet, if, 1135-1136.

Ministry OF Agriculture, Fishieries AND FOOD (1981) Survey of copper and zinc in food. Food Surveillance Paper No 5. London: HMSO.

Snaith, R. P., Constantopoulos, A. A., Jardine, M. Y., et al (1978) A clinical scale for the self assessment of irritability; to be known as the Irritability, Depression, Anxiety (IDA) Scale. British Journal of Psychiatry, 132, 164-171.

\section{Musical hallucinations}

SIR: Fenton \& McRae (Journal, September 1989, $155,401-403$ ) report the case of musical hallucinations in a deaf elderly woman. I would like to report a similar case.

\section{Case Report:}

A 74-year-old widow, living alone, was admitted as an emergency to the acute Psychiatric Unit of the District General Hospital after she had become acutely disturbed. She left her taps on, had broken most of her crockery and was banging on the walls claiming that she was being tormented by hallucinatory voices. All routine investigations were normal, including physical and neurological examinations, full blood count, ESR liver function tests, B12 thyroid screen, chest, skull X-ray, and EEG. Behaviour improved following treatment with trifluoperazine ( $3 \mathrm{mg}$ t.d.s.). She continued, however, to complain of an insistent hallucinatory voice emanating from her vagina - in the form of songs being repeated over and over again, the main ones being 'The Old Rugged Cross', 'Jerusalem', and 'The Hallelujah Chorus'. She was not able to dismiss these hallucinations, and attempts at increasing medication did not bring them under control. The patient was often noted to sing along with the voices; at other times they appeared to irritate her.

Six years before this admission she had begun to complain of vaginal pain. Over the years she was investigated intensively, receiving consultations with a gynaecologist, orthopaedic surgeon, physician, psychologist, and the pain clinic. Apart from some mild atropic vaginitis, no treatable pathology could be found. She was noted to be becoming increasingly deaf, and acquired a hearing aid.

After intensive investigation she was referred to the psychiatry department, the diagnosis then being psychogenic pain, possibly secondary to atypical depression. By this time she had already been on a large number of analgesics and a number of antidepressants, none of which had helped.

She was independent and socially active, having had no previous psychiatric disturbance. She had been married for 44 years, her husband dying suddenly of a cardiovascular arrest 10 years before the admission. Four years after his death she had become involved in a sexual relationship with a man 30 years younger than herself. She felt unhappy and guilty about this relationship, but was unable to end it. The psychologist felt that the development of the pain was an attempt to bring the unsatisfactory relationship to an end. However, despite the fact that the relationship ended, the pain persisted.

She later admitted that she had been hearing the hallucinations from her vagina the whole time, but had changed the symptom into a pain because she felt intensely embarrassed.

This case is interesting in that it outlines several of the features mentioned by Drs Fenton \& McRae: the patient had long-standing deafness, and had embarked on a relationship with another man much younger than herself late in life. The patient was reluctant to report her symptom because of the fear that she would be deemed mad. Although major tranquillisers alleviated the symptom, the problem did not resolve entirely. Detailed psychometric testing was not performed, but there was no evidence of cognitive impairment at the time of presentation, nor on subsequent follow-up.

The Royal Victoria Infirmary

I. MCLOUGHLIN

Queen Victoria Road

Newcastle upon Tyne NE1 4LP

\section{A HUNDRED YEARS AGO}

\section{Hypochondria and hysteria in men and women}

Paget and other authorities have pointed out that hypochondria is much commoner in men than in women. Some physicians are too ready to believe that this aphorism implies a precise homology between hysteria and hypochondria, the former being, so to speak, the form which the latter assumes in woman. Yet few can deny that men are sometimes attacked with a disease bearing all the general symp- toms of hysteria. A man may have hysterical fits, or may show chronic hysteria, becoming bedridden or fancying that a joint is stiff or inflamed. German and Russian authorities have discovered that true hysteria in man is frequent, not in over-civilised countries but among semi-civilised nations, such as the Circassians and Persians. Dr Mendel has recently written a paper in the Deutsche med. Wochenschrift on Hypochondria in the Female Sex. He maintains its distinction from hysteria. He distinguishes three 